\title{
Correction: Microglial inflammation in the parkinsonian substantia nigra: relationship to alpha-synuclein deposition
} \author{
Emilie Croisier*1, Linda B Moran¹, David T Dexter ${ }^{2}$, Ronald KB Pearce ${ }^{1}$ and \\ Manuel B Graeber ${ }^{1}$
}

Address: ${ }^{1}$ Department of Neuropathology, Division of Neuroscience and Mental Health, Imperial College London, and Hammersmith Hospitals Trust, London, UK and ${ }^{2}$ Department of Cellular and Molecular Neuroscience, Division of Neuroscience and Mental Health, Imperial College London, London, UK

Email: Emilie Croisier* - e.croisier@imperial.ac.uk; Linda B Moran - l.moran@imperial.ac.uk; David T Dexter - d.dexter@imperial.ac.uk; Ronald KB Pearce - ronald.pearce@imperial.ac.uk; Manuel B Graeber - m.graeber@imperial.ac.uk

* Corresponding author

Published: 06 April 2006

Journal of Neuroinflammation 2006, 3:9 doi:10.1 186/1742-2094-3-9
Received: 06 April 2006

Accepted: 06 April 2006

This article is available from: http://www.jneuroinflammation.com/content/3/I/9

(C) 2006 Croisier et al; licensee BioMed Central Ltd.

This is an Open Access article distributed under the terms of the Creative Commons Attribution License (http://creativecommons.org/licenses/by/2.0), which permits unrestricted use, distribution, and reproduction in any medium, provided the original work is properly cited.

Upon re-examination of all dates of birth and death of cases described in this paper [1], the ages at death of the following cases presented in Table 1 need to be corrected as follows:

All other clinical information is accurate, and this does not affect the findings of the paper.

\section{References}

I. Croisier E, Moran LB, Dexter DT, Pearce RK, Graeber MB: Microglial inflammation in the parkinsonian substantia nigra: relationship to alpha-synuclein deposition. I Neuroinflammation 2005, 2:14.

Table I:

\begin{tabular}{lll}
\hline Case & Reported age at death & Actual age at death \\
\hline 3 & 71 & 70 \\
6 & 83 & 82 \\
7 & 73 & 72 \\
8 & 77 & 76 \\
9 & 75 & 76 \\
12 & 75 & 74 \\
13 & 83 & 82 \\
14 & 77 & 76 \\
16 & 83 & 84 \\
\hline
\end{tabular}

